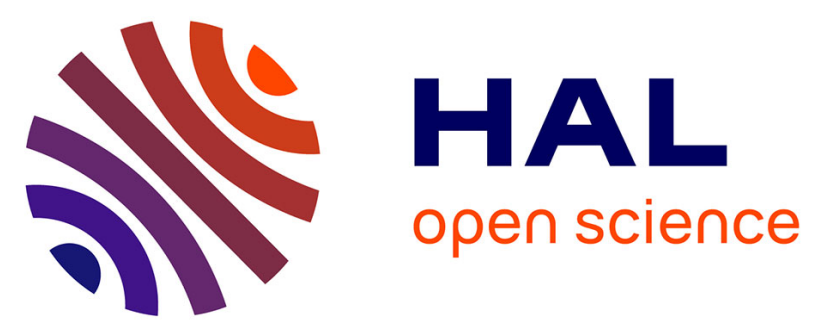

\title{
Phase I-II trial of prolonged gemcitabine infusion plus paclitaxel as a biweekly schedule for advanced breast cancer patients pretreated with anthracyclines
}

\author{
Patrizia Vici, Alessandra Fabi, Giulio Metro, Domenico Sergi, Diana \\ Giannarelli, Luigi Di Lauro, Gerold Bepler, Federica Tomao, Francesco \\ Cognetti, Francesca Conti, et al.
}

\section{To cite this version:}

Patrizia Vici, Alessandra Fabi, Giulio Metro, Domenico Sergi, Diana Giannarelli, et al.. Phase I-II trial of prolonged gemcitabine infusion plus paclitaxel as a biweekly schedule for advanced breast cancer patients pretreated with anthracyclines. Cancer Chemotherapy and Pharmacology, 2010, 67 (3), pp.687-693. 10.1007/s00280-010-1369-y . hal-00596691

\section{HAL Id: hal-00596691 https://hal.science/hal-00596691}

Submitted on 29 May 2011

HAL is a multi-disciplinary open access archive for the deposit and dissemination of scientific research documents, whether they are published or not. The documents may come from teaching and research institutions in France or abroad, or from public or private research centers.
L'archive ouverte pluridisciplinaire HAL, est destinée au dépôt et à la diffusion de documents scientifiques de niveau recherche, publiés ou non, émanant des établissements d'enseignement et de recherche français ou étrangers, des laboratoires publics ou privés. 
Phase I-II trial of prolonged gemcitabine infusion plus paclitaxel as a biweekly schedule for advanced breast cancer patients pretreated with anthracyclines

Patrizia Vici ${ }^{1}$, Alessandra Fabi ${ }^{1}$, Giulio Metro ${ }^{1}$, Domenico Sergi ${ }^{1}$, Diana Giannare $1 i^{1}$, Luigi Di

Lauro $^{1}$, Gerold Bepler ${ }^{2}$, Federica Tomao ${ }^{3}$, Francesco Cognetti ${ }^{1}$, Francesca Conti ${ }^{1}$, Massimo Lopez ${ }^{1}$

${ }^{1}$ Department of Medical Oncology, Regina Elena Cancer Institute, Rome, Italy

${ }^{2}$ Department of Thoracic Oncology, Moffit Cancer Center, Tampa, Florida, USA

${ }^{3}$ Department of Gynecology, University "La Sapienza", Rome, Italy

\section{Corrisponding author:}

Patrizia Vici MD

Division of Medical Oncology B

Regina Elena Cancer Institute

Via Elio Chianesi, 53

00144 Rome, Italy

e-mail: pvici@ifo.it 


\begin{abstract}
Purpose Paclitaxel (PACL) plus gemcitabine (GEM) is an effective regimen for advanced breast cancer patients pretreated with anthracyclines. A prolonged GEM infusion at a fixed-dose rate (FDR) of $10 \mathrm{mg} / \mathrm{m}^{2} / \mathrm{min}$ produces higher levels of intracellular active metabolites of GEM compared with a standard 30-minute infusion. In the present phase I/II trial we investigated the association of FDR GEM plus PACL. Methods $1,200 \mathrm{mg} / \mathrm{m}^{2}$ was the dose of GEM recommended for the phase II study, in which patients received PACL at $150 \mathrm{mg} / \mathrm{m}^{2}$, followed by FDR GEM at $1,200 \mathrm{mg} / \mathrm{m}^{2}$ (total GEM infusion time = 120 minutes), both drugs administered biweekly. Results Fourty-two anthracycline-pretreated advanced breast cancer patients with disease recurrence following at least one line of chemotherapy were enrolled. Two (4.8\%) and 12 (33.3\%) patients experienced a complete and partial response, respectively, for an overall response rate of $38.1 \%$ (95\% CI, 23.4\%-52.8\%). Median progression free survival and overall survival were 5 and 19.9 months, respectively. No statistically significant association was noted between in situ protein expression of RRM1 and BRCA1 (as assessed by immunofluorescence combined with automated quantitative analysis) and response to treatment in 15 patients with tissue available for analysis. Toxicity was mostly mild to moderate, mainly consisting of G3-G4 neutropenia (9.6\%) and hypertransaminasemia (9.5\%). Conclusions Biweekly FDR GEM in combination with PACL is an active and safe regimen for advanced breast cancer patients pretreated with anthracyclines. A prolonged infusion regimen of GEM does not seem to improve the efficacy of a standard 30-minute infusion.
\end{abstract}

Key words: advanced breast cancer; fixed-dose rate; gemcitabine; paclitaxel; HER2-negative breast cancer. 


\section{INTRODUCTION}

Over the last 15 years, the widespread use of anthracyclines in the early stages of breast cancer has changed the clinical scenario of the advanced setting, with many patients developing an anthracycline-refractory disease. Therefore, innovative and active anthracycline-free combinations are needed. Taxanes are among the most active drugs in breast cancer and are widely employed both in the early and advanced setting, either as single-agents or in combination regimens [1]. During the past two decades, many other effective cytotoxics have been introduced in the clinic, including vinorelbine, capecitabine and gemcitabine, thus increasing the therapeutic armamentarium for the management of advanced breast cancer. Among them, gemcitabine (GEM), a deoxyc ytidineanalogue antimetabolite, undergoes intracellular phosphorylation into GEM diphosphate and GEM triphosphate, the two active metabolites to whom the cytotoxic properties of GEM are attributed [2]. On one hand, GEM diphosphate inhibits subunit 1 of ribonucleotide reductase (RRM1), an enzyme involved in normal DNA repair and synthesis. GEM triphosphate competes with the natural nucleotide deoxycytidine triphosphate, for incorporation into DNA during replication, eventually leading to termination of chain elongation and subsequent cell death [2]. Importantly, high levels of expression of RRM1 have been shown to be predictive of resistance to gemcitabine in non-small cell lung cancer (NSCLC) and pancreatic cancer [3,4].

Single-agent GEM showed a good activity and manageable toxicity in advanced breast cancer, with responses as first line treatment ranging from $14 \%$ to $37 \%$ [5]. Given its non-overlapping toxicity, along with its peculiar mechanism of action, GEM represents an attractive drug to be combined with taxanes in anthracycline-pretreated patients. Moreover, preclinical studies had shown an increase in intracellular concentrations of GEM triphosphate with the sequential administration of paclitaxel (PACL) followed by GEM [6,7], potentially resulting into enhanced antitumor activity. Remarkably, phase II studies of first-line PACL/GEM showed responses in as much as $70 \%$ of patients, whereas an activity of $45.5 \%$ to $55 \%$ was observed when PACL/GEM was used as salvage therapy or in anthracycline-pretreated patients [8,9,10]. Preliminary results of a phase III randomized trial of PACL/GEM versus PACL as first-line treatment in advanced breast cancer patients pretreated with anthracyclines showed a significant advantage in terms of response rate and progression free survival for the combination arm [11]. Interestingly, phase I/II studies suggested that biweekly schedule be one of the best ways of administering GEM in combination with PACL. In fact, with biweekly administration a much higher dose-intensity of GEM can be achieved, thus potentially maximizing the synergy of action between PACL and GEM, as evidenced by some clinical trials $[8,12,13,14,15]$.

Notably, pharmacokinetic studies have shown that the doses needed to optimize the accumulation of GEM triphosphate in mononuclear cells are achieved when GEM is administered at a fixed dose- 
rate $\left(F D R\right.$ ) of $10 \mathrm{mg} / \mathrm{m}^{2} / \mathrm{min}[16,17]$. As a result, a prolonged infusion time of $10 \mathrm{mg} / \mathrm{m}^{2} / \mathrm{min}$ may be preferable compared with a standard 30-minute infusion of GEM. To this regard, encouraging results have been observed in phase II trials evaluating FDR GEM either as single-agent or in combination regimens in various solid tumors, including breast cancer [18,19,20,21]. Moreover, a survival advantage was noted for FDR GEM compared with a 30-minute infusion in a randomized phase II study of patients undergoing first-line treatment for advanced adenocarcinoma of the pancreas [22].

Our experience with a biweekly schedule consisting of PACL in combination with a stand ard 30minute infusion of GEM in a very heavily pretreated population with advanced breast cancer, showed very favorable preliminary results and a low toxicity profile [15]. For this reason we designed a phase I/II trial of PACL plus FDR GEM, both administered biweekly, in advanced breast cancer patients pretreated with anthracyclines.

\section{PATIENTS AND METHODS}

We carried out the phase I of the study enrolling 6 patients in each of 3 steps of escalating doses of FDR GEM $\left(1,000,1,100,1,200 \mathrm{mg} / \mathrm{m}^{2}\right)$, in combination with PACL $150 \mathrm{mg} / \mathrm{m}^{2}$; another GEM dose $(900 \mathrm{mg} / \mathrm{m} 2)$ was planned in case of toxicity, but no patient has been enrolled in this step, and 1,200 $\mathrm{mg} / \mathrm{m} 2$ was the recommended dose of GEM for the phase II study.

Forty-two advanced breast cancer patients entered the phase II study. Eligibility criteria included histologically or cytologically confirmed breast cancer pretreated with anthracyclines either in the (neo)adjuvant or advanced setting. To be eligible, patients had to have received at least one line of chemotherapy for advanced disease. In all cases disease progression following the most recent treatment had to be documented. Previous chemotherapy, hormonal therapy and radiotherapy had to be stopped at least 4 weeks prior to study entry. Other eligibility criteria were: presence of evaluable and/or measurable disease, age $\geq 18$ years, Eastern Cooperative Oncology Group performance status $\leq 2$, estimated life expectancy $\geq 12$ weeks and adequate renal, hepatic and hematologic function. Among exclusion criteria there were prior exposure to PACL and/or GEM, presence of symptomatic brain metastases, and history of other malignancy within 5 years of study enrollment with the exception of in situ carcinoma of the cervix and adequately treated non-melanoma skin malignancies. Pregnant or nursing women as well as those with reproductive potential not using an effective contraceptive method were excluded from the study. Supportive treatment was at discretion of the investigator. The study protocol was approved by the local Ethic Committee of the Regina Elena National Cancer Institute and written informed consent was obtained from all patients before study enrollment. 
Treatment consisted of PACL given at $150 \mathrm{mg} / \mathrm{m}^{2}$ as a 3-hour infusion, followed by FDR (10 $\mathrm{mg} / \mathrm{m}^{2} / \mathrm{min}$ ) GEM given at $1,200 \mathrm{mg} / \mathrm{m}^{2}$ (total infusion time $=120$ minutes), both drugs administered on days 1 and 14 of a 28-day cycle. Treatment continued until disease progression, unacceptable toxicity or withdrawal of the patient. Premedication and antiemetic prophylaxis consisted of an antihistaminic, a 5-HT3 receptor antagonist and dexamethasone given as a 15minute infusion before chemotherapy. Treatment was postponed by a maximum of 2 weeks if absolute neutrophil count was less than $1,500 / \mathrm{mL}$ and/or platelet count was less than $100,000 / \mathrm{mL}$ and/or in case of hypertransaminasemia $\geq$ grade 2. Granulocyte Colony Stimulating Factor (G-CSF) was administered in case of grade 4 neutropenia, and a $25 \%$ dose reduction was planned if febrile neutropenia or G3 mucositis occurred. Treatment was discontinued in ca se of persistent grade 3-4 hypertransaminasemia, neurotoxicity and in any case of cycle delay longer than 3 weeks.

Pretreatment evaluation included medical history and physical examination, hematology and blood chemistry, ECG, chest X-ray, and tumor measurement based on standard radiologic methods or physical examination. During the treatment period hematology and blood chemistry were performed on days 1 and 14 of each cycle. Tumor assessments were performed every 3 cycles and every 3 months during the follow-up period. Response to therapy was assessed according to RECIST criteria [23]. Progression-free survival (PFS) was the time elapsed from the date of initiation of treatment to the date of first evidence of disease progression or death. Overall survival (OS) was the time elapsed from the starting date of treatment to the date of death. Toxicity was graded 1-4 according to NCI-CTC (version 3.0).

In an attempt to identify potential predictive factors of sensitivity to the PACL/GEM combination we retrospectively evaluated the in situ protein expression of RRM1 and breast cancer and ovarian susceptibility gene 1 (BRCA1) in primary tumor samples of 15 patients with tissue available for analysis. Tumor samples were evaluated as part of a tissue microarray which included a larger number of advanced breast cancer patients treated with GEM-based chemotherapy at the Regina Elena National Cancer Institute [24]. Analysis of in situ protein expression of RRM1 and BRCA1 was done at the Moffit Cancer Centre in Tampa, Florida. Immunofluorescence combined with automated quantitative analysis [AQUA] was used for the in situ detection and quantification of RRM1 and BRCA1 proteins as described elsewhere [24].

\section{Statistical conside ration}

In the phase I of the study, increasing doses of FDR GEM in combination with PACL $150 \mathrm{mg} / \mathrm{m}^{2}$, both drugs administered as a biweekly schedule, were given to sequential cohorts of patients including 6 individuals each step. Four steps of different doses of GEM were planned: 1,000 $\mathrm{mg} / \mathrm{m}^{2} ; 1,100 \mathrm{mg} / \mathrm{m}^{2} ; 1,200 \mathrm{mg} / \mathrm{m}^{2}$; in the fourth step a dose of $900 \mathrm{mg} / \mathrm{m}^{2}$ was planned in case 
severe toxicity was experienced in the $1^{\text {st }}$ step $\left(1,000 \mathrm{mg} / \mathrm{m}^{2}\right)$, but no patient required dose reduction to $900 \mathrm{mg} / \mathrm{m}^{2}$. Eighteen patients were enrolled in the phase I trial; dose-limiting toxicities (DLT: febrile neutropenia and hyperthransaminasemia) were evaluated during the first 2 cycles of treatment. At GEM dose- level $3\left(1,200 \mathrm{mg} / \mathrm{m}^{2}\right)$, only one hyperthransaminasemia was found among 6 patients, and therefore this level was chosen for the phase II of the trial.

The primary objective of the phase II trial was response rate. The Simon minimax two-stage design was used to determine the sample size. In the first stage, the regimen would be considered worthy of further testing if at least 5 out of 18 eligible patients had an objective response, with a significance level of $5 \%$ and a power of $80 \%$. In the second stage, other 15 patients were needed, with an overall sample size for the phase II of 33 patients. The present analysis is based on data from phase II trial. OS and PFS were estimated by the method of Kaplan and Meyer. Efficacy parameters were evaluated according to an intent-to-treat (ITT) analysis.

\section{RESULTS}

\section{Patients characteristics}

From November 2004 to December 2007, 42 patients were enrolled in the phase II of the study, all evaluable for activity and toxicity. Patients characteristics are listed in table 1 . Median age was 58 years (range 22-78), hormonal receptor status was positive in 35 patients, and 8 patients were HER2 positive, of whom no one had received prior trastuzumab, being all enrolled before 2005 and treated with an anthracycline as first regimen for advanced disease. All patients had been pretreated with anthracyclines either in the (neo)adjuvant or advanced setting, while 21 patients had received prior docetaxel for advanced disease (total patients pretreated with docetaxel $n=22$ ). The median number of previous lines of chemotherapy for advanced disease was 1, although as much as 20 patients had received $\geq 2$ prior lines. Thirty patients had viscera as dominant site of disease, while 27 patients had $\geq 2$ metastatic sites.

\section{Activity}

The median number of administered cycles of PACL/GEM was 6 (range 1-8). Table 2 shows the activity of treatment. Two (4.8\%) complete and 14 (33.3\%) partial responses were observed, for an overall response rate of $38.1 \%$ (95\% CI, 23.4\%-52.8\%). Disease remained stable in 16 patients (38.1\%). Responses by disease site were as follows: 100\% (3/3) for soft tissue, 22\% (2/9) for bone, $37 \%$ (11/30) for visceral lesions, with liver metastasis responding in 21\% (4/19) of patients. Responses were observed also in 8 of the 20 patients $(35 \%)$ pretreated with $\geq 2$ lines of chemotherapy for advanced disease. Partial responses were also reported in 8 out of the 22 patients $(36 \%)$ pretreated with docetaxel, as a confirmation of the lack of complete cross-resistance between 
PACL and docetaxel. Table 3 shows response by hormonal and HER2 receptor status. No differences were observed between groups, but numbers are very small. Overall, the median PFS was 5 months (95\% C.I., 3.4 to 6.6). At a median follow- up of 18 months (range 3-38), the median OS was 19.9 months (95\% C.I., 16.2 to 23.6) (Figure 1a,b).

The average scores for RRM1 and BRCA1 protein expression ranged from 610.65-2047.84 and 200-1399.47, respectively. Median values were 1331.42 for RRM1 and 957.78 for BRCA1. For each marker, median values were chosen to divide patients into a high- and low-expression group. No statistically significant association was noted between RRM1 or BRCA1 and response to treatment $(P=0.4$ for RRM1 and $P=0.4$ for BRCA1 $)$.

\section{Safety}

Toxicity of treatment is reported in Table 4. Overall, hematologic toxicity was usually mild to moderate, with severe (grade 3-4) neutropenia occurring in $9.6 \%$ of the patients. Neutropenic fever was observed in $5(12 \%)$ patients all of whom received G-CSF at subsequent cycles. Mucositis occurred only in one patient (2.5\%) and was grade 1, while nausea/vomiting, mostly of grade 1-2, was recorded in $45.2 \%$ of patients. Grade 1-2 sensory neuropathy was encountered in $59.5 \%$ of patients, being of grade 3 in only one patient (2.5\%). Transient and reversible grade 1-2 hypertransaminasemia occurred in more than half of patients $(52.6 \%)$. All the 4 patients $(9.5 \%)$ experiencing a severe hypertransaminasemia had liver metastases at baseline. Fatigue and musculoskeletal pain were related to the total cumulative dose, mostly occurring after the $3^{\text {rd }}-4^{\text {th }}$ cycle of treatment. Alopecia was universal. Not any case of cardiotoxicity related to the study drugs, as well as no toxic deaths, were observed. A $25 \%$ dose reduction was required in only 1 patient (2.4\%), due to grade 4 hypertransaminasemia. Treatment was delayed in 2 patients $(4.8 \%)$ owing to reversible grade 2 hypertransaminasemia, and was discontinued in 1 patient $(2.4 \%)$ because of grade 3 sensory neuropathy.

\section{DISCUSSION}

Regardless of hormonal and HER2 receptor status, chemotherapy remains an important component of the management of advanced breast cancer patients. The "optimal" treatment of pretreated patients depends on a number of variables, such as molecular issues, sites of disease and previous therapy. Particularly, for patients with HER2-negative advanced breast cancer there is an urgent need of innovative and effective anthracycline-free combination regimens. Also, improved activity of chemotherapy may derive from scheduling variation, in order to better exploit pharmacokinetic and pharmacodynamic interactions of the drugs employed. The use of a combination of a taxane plus gemcitabine is among the best treatment options for HER2-negative advanced breast cancer 
patients who have been pretreated with anthracyclines [25,26,27]. Although phase III comparisons between PACL/GEM and docetaxel/GEM are lacking, a small randomized phase II study suggested that PACL be the best taxane to be combined with GEM on account of a safer toxicity profile of PACL/GEM compared with docetaxel/GEM [28].

In the present trial, FDR GEM in association with PACL produced a response rate of $38.1 \%$, which is slightly inferior to the $45.5 \%$ to $55 \%$ of responses reported with the same combination in phase II studies of pretreated patients [25]. Several reasons could be put forward in order to explain this finding. Firstly, more than $70 \%$ of patients in our trial had visceral disease and nearly half of all patients had been pretreated with $\geq 2$ lines of chemotherapy for advanced disease. Secondly, the population of our trial included $19 \%$ of patients with HER2-positive breast cancer, a disease entity known to be associated with a particularly aggressive clinical course in the absence of treatment with anti-HER2 drugs such as the monoclonal antibody trastuzumab [29]. Moreover a pharmacokinetic study evaluating FDR GEM with or without PACL in patients with NSCLC, suggested the presence of inter- and intra-patients variability in the plasmatic concentrations of GEM [30]. Such a finding suggests that individualization of the dose rate could be crucial in order to achieve effective dosing of GEM. More recently, a randomized crossover study of GEM 1,000 $\mathrm{mg} / \mathrm{m}^{2}$ given as a 30 -minute versus a FDR infusion at $10 \mathrm{mg} / \mathrm{m}^{2} / \mathrm{min}$ carried out in 33 patients, showed that intracellular accumulation of GEM was greater with the prolonged infusion, but there was an increase in GEM-triphosphate accumulation between weeks 1 and 2, indicating a selfinduction of GEM accumulation [31]. Also, a significant heterogeneity of GEM triphosphate was noted, thus suggesting that the optimal dose rate needed to optimize intracellular accumulation of GEM triphosphate may change overtime, and a fixed dose rate of $10 \mathrm{mg} / \mathrm{m}^{2} / \mathrm{min}$ could not be optimal for all patients and for the same patient over time [31]. Nevertheless, despite all these considerations, in the present study FDR GEM plus PACL given biweekly was not able to improve the remarkable response rate of 53\% observed in final results of our previous experience with the use of a similar schedule of PACL/GEM with GEM given as a standard 30-minute infusion [32].

Importantly, the identification of women who will benefit from palliative chemotherapy would allow physicians to deliver effective treatments to sensitive patients, while preventing others from suffering the side effects of inactive drugs. Unfortunately, in this trial we did not observe any significant correlation between response to treatment and RRM1 or BRCA1, two biomarkers which could predict sensitivity to GEM and taxanes, respectively [3,33]. However, only 15/42 patients in the present trial had tissue available for analysis of RRM1 and BRCA1, and this small sample should be regarded as one of the reasons for the negative results observed. Neverthless the search for biomarkers that could predict response to treatment should be pursued actively in future clinical trials of breast cancer. To date, estrogen receptor (ER)- $\alpha$, progesterone receptor $(\mathrm{PgR})$ and HER2 
represent the only biomarkers used in clinical practice to aid treatment decisions in both early and advanced breast cancer.

Importantly, we observed a very favorable toxicity profile for FDR GEM plus PACL, especially for hematologic toxicity. Also, toxicity was manageable and reversible with few treatment delays. Of note, only one patient had to discontinue treatment owing to toxicity, namely a grade 3 sensory neuropathy related to PACL. The low toxicity observed in the present trial confirm that dose intensification obtained by prolonging GEM infusion is safe in advanced breast cancer [21]. Interestingly, the good safety profile of FDR GEM might not apply to all cancers, particularly in NSCLC, in which FDR GEM, given as single-agent in patients not eligible for platinum-based chemotherapy, was found to be associated with an unacceptable rate of hematologic toxicity compared with a standard 30-minute infusion [34].

In conclusion, FDR GEM plus PACL showed to be active and safe in advanced breast cancer patients pretreated with anthracyclines. However, the prolonged GEM infusion did not seem to offer a clinical advantage over a standard infusion regimen, according to other literature results failing to demonstrate an advantage in various solid tumors [35,36,37]. Importantly, following the positive results of antiangiogenic therapies for HER2-negative breast cancer [38], the association of a taxane/GEM doublet with the anti-VEGF agent bevacizumab is currently one of the most appealing strategies, and several trials are being conducted in order to evaluate this three-drug regimen $[39,40]$.

Conflict of interest statement. The authors indicated no potential conflicts of interest. 


\section{REFERENCES}

1. King KM, Lupichuk S, Baig L, Webster M, Basi S, Whyte D, Rix S (2009) Optimal use of taxanes in metastatic breast cancer. Curr Oncol 16:8-20

2. Plunkett W, Huang P, Xu YZ, Heinemann V, Grunewald R, Gandhi V (1995) Gemcitabine: mtabolism, mechanisms of action, and self-potentiation. Semin Oncol 22(S11):3-10

3. Bepler G, Kusmartseva I, Sharma S, Gautam A, Cantor A, Sharma A, Simon G (2006) RRM1 modulated in vitro and in vivo efficacy of gemcitabine and platinum in non-small-cell lung cancer. J Clin Oncol 24:4731-4737

4. Nakahira S, Nakamori S, Tsujie M, Takahashi Y, Okami J, Yoshioka S, Yamasaki M, Marubashi S, Takemasa I, Miyamoto A, Takeda Y, Nagano H, Dono K, Umeshita K, Sakon M, Monden M (2007) Involvement of ribonucleotide reductase M1 subunit overexpression in gemcitabine resistance of human pancreatic cancer. Int J Cancer 120:1355-1363

5. Blackstein M, Vogel CL, Ambinder R, Cowan J, Iglesias J, Melemed A (2002) Gemcitabine as first-line therapy in patients with metastatic breast cancer: a phase II trial. Oncology 62:2-8

6. Kroep JR, Giaccone G, Voorn DA, Smit EF, Beijnen JH, Rosing H, van Moorsel CJ, van Groeningen CJ, Postmus PE, Pinedo HM, Peters GJ (1999) Gemcitabine and paclitaxel: pharmacokinetic and pharmacodynamic interactions in patients with non-small-cell lung cancer. J Clin Oncol 17:2190-7

7. Kroep JR, Giaccone G, Tolis C, Voorn DA, Loves WJ, Groeningen CJ, Pinedo HM, Peters GJ (2000) Sequence dependent effect of paclitaxel on gemcitabine metabolism in relation to cell cycle and cytotoxicity in non-small-cell lung cancer cell lines. Br J Cancer 83:1069-1976

8. Colomer R, Llombart-Cussac A, Lluch A, Barnadas A, Ojeda B, Carañana V, Fernández Y, García-Conde J, Alonso S, Montero S, Hornedo J, Guillem V (2004) Biweekly paclitaxel plus gemcitabine in advanced breast cancer: phase II trial and predictive value of HER2 extracellular domain. Ann Oncol 15:201-6

9. Delfino C, Caccia G, Gonzáles LR, Mickiewicz E, Rodger J, Balbiani L, Morales DF, Comba AZ, Brosio C (2004) Gemcitabine plus paclitaxel as first-line chemotherapy for patients with advanced breast cancer. Oncology 66:18-23

10. Murad AM, Guimarães RC, Aragão BC, Scalabrini-Neto AO, Rodrigues VH, Garcia R (2001) Phase II trial of the use of paclitaxel and gemcitabine as a salvage treatment in metastatic breast cancer. Am J Clin Oncol 24:264-8

11. O'Shaughnessy J, Nag S, Calderillo-Ruiz G, Jordaan J, Llombart A, Pluzanska A, Pawlicki M, Reyes JM, Sekhon J, Albain KS (2003) Gemcitabine plus paclitaxel (GT) versus paclitaxel (T) 
as first-line treatment for anthracycline pre-treated metastatic breast cancer (MBC): Interim results of a global phase III study. Proc Am Soc Clin Oncol; 22(abstract 25)

12. Rothenberg ML, Sharma A, Weiss GR, Villalona-Calero MA, Eckardt JR, Aylesworth C, Kraynak MA, Rinaldi DA, Rodriguez GI, Burris HA 3rd, Eckhardt SG, Stephens CD, Forral K, Nicol SJ, Von Hoff DD (1998) Phase I trial of paclitaxel and gemcitabine administered every two weeks in patients with refractory solid tumors. Ann Oncol 9:733-738

13. Sanchez P, Medina MB, Mohedano N, Jaen A, Porras I, Gonzales E, Fernandez M, Lozano A (1998) Results from a phase II study of gemcitabine in combination with paclitaxel in metastatic breast cancer. Ann Oncol 9(S4):77P(abstract)

14. Colomer R, Llombart A, Lluch A, Ojeda B, Barnadas A, Carañana V, Fernández Y, De Paz L, Guillem V, Alonso S (2000) Paclitaxe1/gemcitabine administered every two weeks in advanced breast cancer: preliminary results of a phase II trial. Semin Oncol27(S2):20-24

15. Vici P, Foggi P, Capomolla E, Santiccioli S, Cauchi C, Giacinti L, Lopez M (2002) Biweekly paclitaxel/gemcitabine $(\mathrm{P} / \mathrm{G})$ as salvage treatment in breast cancer patients (pts): preliminary result. Proc Am Soc Clin Oncol 21 (abstract 2054)

16. Abbruzzese JL, Grunewald R, Weeks EA, Gravel D, Adams T, Nowak B, Mineishi S, Tarassoff P, Satterlee W, Raber MN (1991) A phase I clinical, plasma, and cellular pharmacology study of gemcitabine. J Clin Oncol 9:491-498

17. Grunewald R, Kantarjian H, Du M, Faucher K, Tarassoff P, Plunkett W (1992) Gemcitabine in leukemia: a phase I clinical, plasma, and cellular pharmacology study. J Clin Oncol 10:406-413

18. Ceribelli A, Gridelli C, De Marinis F, Fabi A, Gamucci T, Cortesi E, Barduagni M, Antimi M, Maione P, Migliorino MR, Giannarelli D, Cognetti F (2003) Prolonged gemcitabine infusion in advanced non-small cell lung carcinoma: a randomized phase II study of two different schedules in combination with cisplatin. Cancer 98:337-343

19. Schmid P, Akrivakis K, Flath B, Grosse Y, Sezer O, Mergenthaler HG Possinger K (1999) Phase II trial of gemcitabine as prolonged infusion in metastatic breast cancer. Anticancer Drugs 10:625-631

20. Feliu J, Mel R, Borrega P, López Gómez L, Escudero P, Dorta J, Castro J, Vázquez-Estévez SE, Bolaños M, Espinosa E, González Barón M (2002) Phase II study of a fixed dose-rate infusion of gemcitabine associated with uracil/tegafur in advanced carcinoma of the pancreas. Ann Oncol 13:1756-62

21. Estephan F, Valero V, Esteva FJ, Mejia JA, Frye DK, Ibrahim NK (2009) Phase I study of prolonged-infusion gemcitabine combined with cyclophosphamide in patients with metastatic carcinoma of the breast: tolerability of an optimal dose schedule. Oncology 77:63-70 
22. Tempero M, Plunkett W, Ruiz Van Haperen V, Hainsworth J, Hochster H, Lenzi R, Abbruzzese J (2003) Randomized phase II comparis on of dose-intense gemcitabine: thirty-minute infusion and fixed dose rate infusion in patients with pancreatic adenocarcinoma. J Clin Oncol 21:34023408

23. Therasse P, Arbuck SG, Eisenhauer EA, Wanders J, Kaplan RS, Rubinstein L, Verweij J, van Glabbeke M, van Oosterom AT, Christian MC, Gwyther SG (2000) New guidelines to evaluate the response to treatment in solid tumors. J Natl Cancer Inst 92:205-216

24. Metro G, Zheng Z, Fabi A, Schell M, Antoniani B, Mottolese M, Monteiro AN, Vici P, Lara Rivera S, Boulware D, Cognetti F, Bepler G (2010) In situ protein expression of RRM1, ERCC1, and BRCA1 in metastatic breast cancer patients treated with gemcitabine-based chemotherapy. Cancer Invest 28:172-180

25. Metro G, Fabi A, Russillo M, Papaldo P, De Laurentiis M, Ferretti G, Pellegrini D, Nuzzo C, Graziano V, Vici P, Introna M, Felici A, Cognetti F, Carlini P (2008) Taxanes and gemcitabine doublets in the management of HER-2 negative metastatic breast cancer: towards optimization of association and schedule. Anticancer Res 28:1245-58

26. Albain KS, Nag SM, Calderillo-Ruiz G, Jordaan JP, Llombart AC, Pluzanska A, Rolski J, Melemed AS, Reyes-Vidal JM, Sekhon JS, Simms L, O'Shaughnessy J (2008) Gemcitabine plus Paclitaxel versus Paclitaxel monotherapy in patients with metastatic breast cancer and prior anthracycline treatment. J Clin Oncol 26:3950-7

27. Gudena V, Montero AJ, Glück S (2008) Gemcitabine and taxanes in metastatic breast cancer: a systematic review. Ther Clin Risk Manag 4:1157-1164

28. Khoo KS, Manzoor Zaidi SH, Srimuninnimit V, Song S, Nair R, Ngelangel CA, Bustam A, Reece WH, Lehnert M (2006) Gemcitabine and split-dose paclitaxel or docetaxel in metastatic breast cancer: a randomised phase II study. Eur J Cancer 42:1797-1806

29. Dawood S, Broglio K, Buzdar AU, Hortobagyi GN, Giordano SH (2010) Prognosis of women with metastatic breast cancer by HER2 status and trastuzumab treatment: an institutional-based review. J Clin Oncol 28:92-98

30. Shord SS, Faucette SR, Gillenwater HH, Pescatore SL, Hawke RL, Socinski MA, Lindley C (2003) Gemcitabine pharmacokinetics and interaction with paclitaxel in patients with advanced non-small-cell lung cancer. Cancer Chemother Pharmacol 51:328-336

31. Grimison P, Galettis P, Manners S, Jelinek M, Metharom E, de Souza PL, Liauw W, Links MJ (2007) Randomized crossover study evaluating the effect of gemcitabine infusion dose rate: evidence of auto-ind uction of gemcitabine accumulation. J C lin Oncol 25:5704-5709

32. Vici P, Capomolla E, Foggi P, Carpano S, Conti F, Paoletti G, Cauchi C, Giacinti L, Leonetti C, Giannarelli D, Lopez M (2006) High activity of salvage treatment with biweekly paclitaxel- 
gemcitabine combination in heavily pretreated breast cancer patients. J Exp Clin Cancer Res 25:39-44

33. De Ligio JT, Velkova A, Zorio DA, Monteiro AN (2009) Can the status of the breast and ovarian cancer susceptibility gene 1 product (BRCA1) predict response to taxane-based cancer therapy? Anticancer Agents Med Chem 9:543-549

34. Cappuzzo F, Novello S, De Marinis F, Selvaggi G, Scagliotti GV, Barbieri F, Maur M, Papi M, Pasquini E, Bartolini S, Marini L, Crinò L (2006) A randomized phase II trial evaluating standard $(50 \mathrm{mg} / \mathrm{min})$ versus low $(10 \mathrm{mg} / \mathrm{min})$ infusion duration of gemcitabine as first- line treatment in advanced non-small-cell lung cancer patients who are not eligible for platinumbased chemotherapy. Lung Cancer 52:319-25

35. Gridelli C, Gallo C, Ceribelli A, Gebbia V, Gamucci T, Ciardiello F, Carozza F, Favaretto A, Daniele B, Galetta D, Barbera S, Rosetti F, Rossi A, Maione P, Cognetti F, Testa A, Di Maio M, Morabito A, Perrone F (2007) Factorial phase III randomised trial of rofecoxib and prolonged constant infusion of gemcitabine in advanced non-small-cell lung cancer: the GEmcitabineCOxib in NSCLC (GECO) study. Lancet Oncol 8:500-12

36. Gridelli C, De Maio E, Barbera S, Sannicolo M, Piazza E, Piantedosi F, Brancaccio L, Morabito A, Maione P, Renda F, Signoriello G, Perrone F (2008) The MILES-2G phase 2 study of single-agent gemcitabine with prolonged constant infusion in advanced non-small cell lung cancer elderly patients. Lung Cancer 61:67-72

37. Poplin E, Feng Y, Berlin J, Rothenberg ML, Hochster H, Mitchell E, Alberts S, O'Dwyer P, Haller D, Catalano P, Cella D, Benson AB $3^{\text {rd }}$ (2009) Phase III, randomized study of gemcitabine and oxaliplatin versus gemcitabine (fixed-dose rate infusion) compared with gemcitabine (30-minute infusion) in patients with pancreatic carcinoma E6201: a trial of the Eastern Cooperative Oncology Group. J Clin Oncol 27:5859

38. Miller K, Wang M, Gralow J, Dickler M, Cobleigh M, Perez EA, Shenkier T, Cella D, Davidson NE (2007) Paclitaxel plus bevacizumab versus paclitaxel alone for metastatic breast cancer. N Engl J Med 357:2666-2676

39. Phase II Gemzar, Taxol \& Avastin Combination as 1st Line Tx for Metastatic Breast CA. Available from URL:

http://clinicaltrials.gov/ct2/show/NCT00403130?term=bevacizumab+and+gemcitabine+and+br east+cancer\&rank=11 [accessed March 1, 2010]

40. Docetaxel, Gemcitabine and Bevacizumab for Metastatic Breast Cancer. Available from URL: http://clinicaltrials.gov/ct2/show/NCT00754351?term=bevacizumab+and+gemcitabine+and+br east+cancer\&rank=2 [accessed March 1, 2010] 
Table 1. Patient characteristics

\begin{tabular}{|c|c|}
\hline Characteristic & No. of pts \\
\hline Entered/evaluable & $42 / 42$ \\
\hline Median age (range) & $58(22-78)$ \\
\hline Median performance status (range) & $0(0-2)$ \\
\hline Premenopausal & $6 / 36$ \\
\hline \multicolumn{2}{|l|}{ Hormonal receptor status (ER and/or PgR) } \\
\hline Positive & 35 \\
\hline Negative & 7 \\
\hline \multicolumn{2}{|l|}{ HER2 status } \\
\hline Positive & 8 \\
\hline Negative & 25 \\
\hline Unknown & 9 \\
\hline Prior hormonal treatment (adjuvant/ad vanced) & $35(20 / 34)$ \\
\hline Prior (neo)adjuvant chemotherapy (anthracycline/docetaxel) & $25(11 / 1)$ \\
\hline \multicolumn{2}{|l|}{ Prior chemotherapy for advanced disease } \\
\hline Anthracycline & 16 \\
\hline Docetaxel & 21 \\
\hline Anthracycline and docetaxel & 15 \\
\hline Other cytotoxics & 5 \\
\hline Median no. of prior lines of chemotherapy for advanced disease (range) & $1(1-4)$ \\
\hline \multicolumn{2}{|l|}{ Dominant metastatic site } \\
\hline Soft tissue & 3 \\
\hline Bone & 9 \\
\hline Viscera (liver) & $30(19)$ \\
\hline \multicolumn{2}{|l|}{ No. of disease sites } \\
\hline 1 & 15 \\
\hline 2 & 23 \\
\hline 3 & 4 \\
\hline
\end{tabular}


Table 2. Activity of treatment

\begin{tabular}{|c|c|c|}
\hline $\mathrm{N}$ & $\%$ & \multirow{5}{*}{$38.1 \%(95 \%$ CI, $23.4 \%-52.8 \%)$} \\
\hline CR 2 & $4.8\}$ & \\
\hline PR 1 & 33.3 & \\
\hline $\mathrm{NC} 1$ & 38.1 & \\
\hline PD 1 & 23.8 & \\
\hline
\end{tabular}


Table 3. Response to treatment by hormonal receptor and HER2 status

\begin{tabular}{|lcc|}
\hline ER and/or PgR + & $\mathbf{N}^{\circ}$ & $\mathbf{\%}$ \\
\cline { 2 - 3 } ER and/or PgR - & $3 / 35$ & 37.1 \\
HER-2 + & $4 / 8$ & 42.8 \\
HER-2 - & $9 / 25$ & 36.0 \\
\hline
\end{tabular}


Table 4. Summary of treatment-related adverse events in 42 patients

\begin{tabular}{|lccc|}
\hline Toxicity & \multicolumn{3}{c|}{ Grade $(\%)$} \\
\cline { 2 - 4 } Neutropenia & $\mathbf{1 - 2}$ & $\mathbf{3}$ & $\mathbf{4}$ \\
Febrile neutropenia & $18(42.8)$ & $2(4.8)$ & $2(4.8)$ \\
Thrombocytopenia & - & $3(7.1)$ & $2(4.8)$ \\
Anemia & $9(21.4)$ & $0(0)$ & $0(0)$ \\
Mucositis & $29(69)$ & $1(2.4)$ & $0(0)$ \\
Nausea/vomiting & $1(2.4)$ & $0(0)$ & $0(0)$ \\
Sensory neuropathy & $18(42.8)$ & $1(2.4)$ & $0(0)$ \\
Alopecia & $25(59.5)$ & $1(2.4)$ & $0(0)$ \\
Hypertransaminasemia & $22(52.6)$ & $3(7.1)$ & $0(0)$ \\
Fatigue & $14(33.3)$ & $1(2.4)$ & $0(2.4)$ \\
Musculoskeletal pain & $10(23.8)$ & $0(0)$ & $0(0)$ \\
\hline
\end{tabular}


Legend of Figure:

Fig. 1: Progression free survival (a) and overall survival (b) in 42 enrolled patients 
a

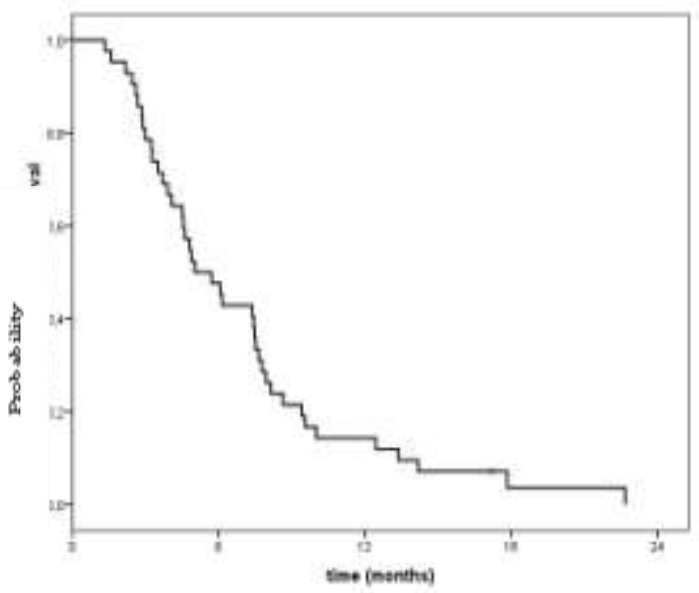

b

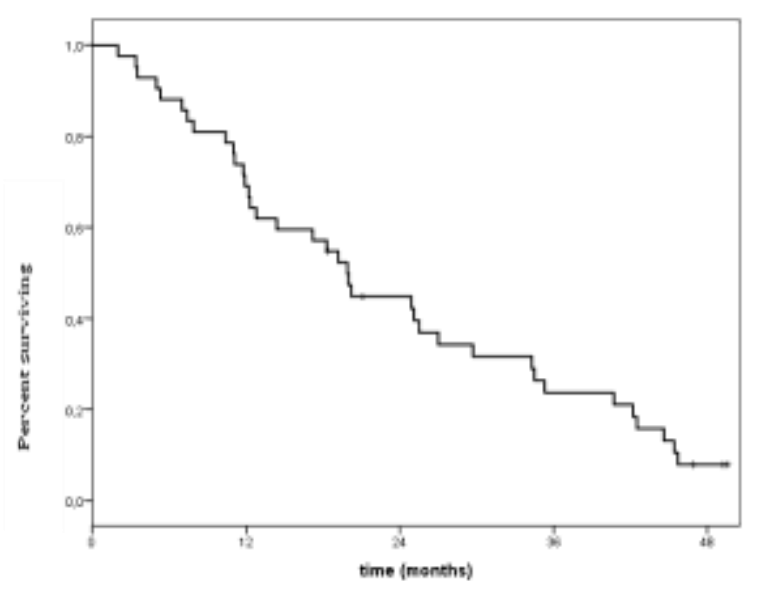

